\title{
Process Optimization for Post Disaster Reconstruction Project Based on Industrial Design Structure Matrix (DSM)
}

Qingping Zhong

Sichuan University

Hui Tang

Sichuan University

Chuan Chen ( $\nabla$ cchenscu@sina.com)

Sichuan University

\section{Research Article}

Keywords: post-disaster reconstruction, design structure matrix (DSM), construction process optimization, project delivery method, integration

Posted Date: November 30th, 2021

DOI: https://doi.org/10.21203/rs.3.rs-1107331/v1

License: () (i) This work is licensed under a Creative Commons Attribution 4.0 International License. Read Full License 


\section{Abstract}

Post-disaster reconstruction projects face tighter time constraints and are in a more complex environment, making the implementation process of conventional projects unable to meet new requirements. This study decomposes the construction process and then determines the feed-forward and feedback relationship between activities in the post-disaster reconstruction environment. An information relationship diagram is established, and the relationship is transformed into a design structure matrix (DSM). Through DSM manipulation, a partitioned DSM is formed to express the activity process that is more suitable for reconstruction. This research shows that the activities sequence and content need to be changed to adapt to the reconstruction scenario, and some activities may even be canceled. Some suggestions can help construct the project faster, including closer cooperation between design and construction. The bidding scope includes design and construction and the use of more integrated project delivery methods. Finally, a reconstruction case in China illustrates the operability of analyzing and adjusting the implementation process through this framework.

\section{Introduction}

In recent years, the frequency of disasters and losses has been increasing. According to CRED, only in 2019, 396 natural disasters were recorded in EM-DAT with 11,755 deaths, 95 million people affected, and 103 billion US\$ in economic losses across the world[1]. Buildings and infrastructure, which are the physical basis of people's livelihood, are often irreversibly damaged when disasters occur. A building or infrastructure must be appropriately designed and constructed to meet the victims' cultural, social, and physical requirements and provide a set of safe facilities to protect them from possible environmental hazards.

Reconstruction projects can be defined as modification, functional conversion, or reset of existing facilities[2, 3]. Usually, public services and infrastructure are typically restored to normal by expanding space, interior and exterior decoration, and improving functions [4]. A post-disaster reconstruction project is still a branch of the construction project in a specific environment, so it still needs to follow the essential requirements and process of construction. However, unlike conventional construction projects, post-disaster reconstruction is always in a dynamic and uncertain environment. A construction project needs to deeply identify the owner's requirements in advance and establish goals based on these requirements. Among all the reconstruction goals and requirements, time requirement is undoubtedly the most urgent [5]. Completing the project construction at the fastest speed will help restore the economy and society of the disaster-stricken area to normal. In addition, putting the facilities in the disaster area into use as soon as possible helps test the systemic capabilities of different facilities and improve the ability to withstand future disasters.

Conventional construction projects have a lot of techniques and methods to shorten the project time and have some delivery methods to work together. PMBOK proposes two time-compression techniques, such as crashing and fast tracking[6]. The crashing technique needs the additional resources input that limits the use of this method. The fast-tracking technique overlaps some activities that were initially carried out in sequence. In the practice of reconstruction, whether the activities are moved forward or overlapped is more based on the manager's experience and the influence from external stakeholders rather than structured analysis. The complex situation of the reconstruction leads to changes in the assumptions of the technique's application, and the conventional technical process needs to be adjusted to suit the new conditions.

Some scholars have put forward suggestions on the post-disaster reconstruction model [7], however, these suggestions are more from the perspective of performance evaluation of existing projects rather than from the internal process of the project, which may lead to inappropriate decisions. When managing reconstruction projects, there are some issues that scholars and decision makers should notice:

$1 \otimes W h e t h e r$ the traditional project implementation process needs to be adjusted to meet the unique requirements of the reconstruction scenario $\mathbb{Z}$

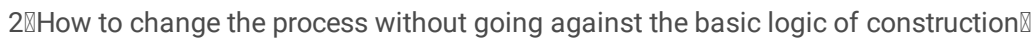

$3 \llbracket$ After changing the activities in the process, how to carry out effective management $\$

This article attempts to reorganize the implementation process of the reconstruction project in the post-disaster environment, establish a project process model to shorten the project time, and find the most suitable reconstruction delivery method to aid. The model is based on the general construction process and analyzes the interdependence between activities in a reconstruction environment. Using the DSM method to rearrange the activity process, highlight the activities with iteration and coupling relationship, and provide help for adjusting the organization of activities.

\section{Literature Review}

\section{1 disaster management}

Traditionally, disaster management is generally considered a spiraling cyclical process [8], from pre-disaster preparation to emergency response and then reconstruct various facilities in the disaster-stricken area to finally achieve a higher degree of disaster preparedness. Alexander believed that disasters are often recurring events. He considers disaster management a cycle formed by the four stages of mitigation, preparation, response, and recovery[9]. In recent years, the concept of resilience has been introduced and integrated into disaster management theory and has become a positive measure for disaster management $[10,11]$, which is defined as the ability of a system, community, or society to adapt to dangers, through resistance or change, to achieve and maintain an acceptable level of function and structure [12],

Among the four stages of disaster management, the recovery stage usually occurs after the disaster relief stage, ranging from three months to five years, or even longer [13]. Generally, the recovery includes psychological recovery and socio-economic recovery. The socio-economic recovery emphasized by FEMA contains five categories, namely: economic, health and social services, housing, infrastructure systems, and natural \& cultural resources [14]. The 
reconstruction of housing and infrastructure systems with appropriate advanced functions and reliable quality is the physical basis for social services and economic recovery. At the same time, the restoration goals of economic and social services have guided the upgrading of the functions and construction methods of housing and infrastructure.

\section{2 the process of post-disaster reconstruction}

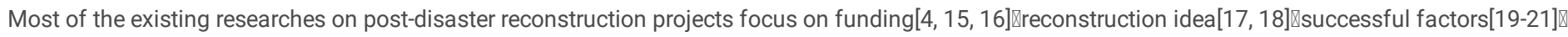
community participation[22, 23]凶Availability and effective management of resources [24,25]. These studies are less concerned about the project's implementation process, so it isn't easy to guide the behavior of managers.

Post-disaster reconstruction projects should be regarded as special projects and implemented according to the guidance of project management knowledge [26]. Silva believed that the reconstruction project still needs to include three stages: planning, design, and construction. Scholars and practitioners have identified many goals and challenges for post-disaster reconstruction, such as deliver on time, within budget, higher quality standards, multiple participants, etc. [27-30]. Time or speed has become a standard for measuring the success of reconstruction [5]. Gradually replacing the normal process in the built environment in a very short and tight time was considered the critical difference between post-disaster and normal conditions [31].

Although post-disaster reconstruction might be a relatively long process (more than twelve months) compared with disaster response, it still needs to make rapid progress. Many scholars agree that time has a positive effect on reconstruction projects. Still, only a few studies have focused on adjusting the construction process to achieve the goal of shortening the construction period [5, 31]. Norling believed the first step in implementing an effective time management process was to create a schedule list that reflected the action plan [5]. Fatazi\&Arefian revealed the causes and effects of four different segmentations on the time compression of the reconstruction project[32]. Olshansky\&Hopkins argued the time compression could improve the design of planning processes and structure of institutions following disasters[31].

PMI proposed crashing and fast-tracking techniques to shorten the project time, which has become the starting point of many studies[6]. Crashing shortens the duration by increasing resources, including working overtime, inputting additional resources, or paying to speed up activities on the critical path[6]. The traditional CPM scheduling optimization is based on this method. Scholars have developed different methods of shortening project time based on crashing [33-35] to cope with various constraints, such as resources constraints and time-cost tradeoffs.

The fast-tracking technique overlaps part or all of the activities or stages usually completed sequentially[6]. For example, the foundation of the building is constructed before all architectural drawings are complete. Researchers value this method more because it breaks through resource constraints and emphasizes optimizing the management process[36-39]. The time reduced caused by overlapping activities depends on two aspects: the reduced time of overlapping activities and the increased time of rework caused by insufficient information [40, 41].

When activities overlap, specific project delivery methods are required to cooperate. DBB, DB(and similar EPC), and CMR are currently the three most mainstream delivery methods in the industry[42], which affect the project's delivery time by varying the number of contractors, responsibility distribution, and process. In DBB, the owner signs contracts with three different entities respectively and awards the contracts at different times in sequence. Limited by contract authorization, it is difficult for authorized entities to participate in the activities of other entities. DB and CMR have a manager who assumes the main responsibility or risk, and the builder provides constructability suggestions at the early stage of the design process. In two later project delivery processes, the designer/builder controls the details of the design[43], and it is possible to integrate construction and design into a whole rather than fragmented work.

\section{3 the design structure matrix (DSM) method}

The design structure matrix (DSM), also called the dependency structure matrix, has become a widely used modeling tool in many areas such as product development and system design[44, 45]. In project management, DSM can be used to express and analyze activity dependencies [46-48]. The project schedule results from the superposition of the activities sequence and the feedback to a certain extent. Traditional CPM and PERT tools can no longer handle much activity information feedback and iterative loops of complex projects [49]. DSM overcomes these shortcomings and is used to improve project schedule performance [50-52].

The DSM is a graphical modeling tool used to represent a system's elements and their interactions[53]. The DSM can be four categories: component-based DSM, team-based DSM, activity-based DSM, parameter-based DSM[54]. The activity-based DSM is usually used in Project scheduling, activity sequencing, and cycle time reduction[46]. The DSM approach allows the project or engineering manager to represent meaningful task relationships to determine a sensible sequence for the modeled activities [55]. The DSM has been identified as a potential tool to model interdependent activities (or loops), to identify suitable assumptions, formulate and evaluate the resulting sequence [47]. The DSM types and analysis methods are shown in Table 1.

\section{Table 1 Four Different Types of Data in DSM [adapted from 54]}




\begin{tabular}{|c|c|c|c|}
\hline $\begin{array}{l}\text { DSM Data } \\
\text { Types }\end{array}$ & Representation & Application & Analysis Method \\
\hline \multirow[t]{4}{*}{ Activity-based } & \multirow[t]{4}{*}{ Task/Activity input-output relationship } & \multirow{4}{*}{$\begin{array}{l}\text { Project scheduling, } \\
\text { activity sequencing, } \\
\text { cycle time reduction }\end{array}$} & Partitioning, \\
\hline & & & Tearing, \\
\hline & & & Banding, \\
\hline & & & $\begin{array}{l}\text { Simulation and Eigenvalue } \\
\text { Analysis }\end{array}$ \\
\hline \multirow[t]{4}{*}{$\begin{array}{l}\text { Parameter- } \\
\text { based }\end{array}$} & \multirow[t]{4}{*}{$\begin{array}{l}\text { Parameter decision points and necessary } \\
\text { precedents }\end{array}$} & \multirow{4}{*}{$\begin{array}{l}\text { Low-level activity sequencing and process } \\
\text { construction }\end{array}$} & Partitioning, \\
\hline & & & Tearing, \\
\hline & & & Banding, \\
\hline & & & $\begin{array}{l}\text { Simulation and Eigenvalue } \\
\text { Analysis }\end{array}$ \\
\hline Team-based & Multi-team interface characteristics & $\begin{array}{l}\text { Organizational design, interface management, team } \\
\text { integration }\end{array}$ & Clustering \\
\hline $\begin{array}{l}\text { Component- } \\
\text { based }\end{array}$ & Multi-component relationship & System architecting, engineering and design & Clustering \\
\hline
\end{tabular}

The basic representation of task DSM is an N-square matrix containing a list of activities in the rows and columns in the same order. The order of activities in the rows or columns indicates the execution sequence. The marks represent the information flow between activities. The relationships among the activities are represented with the help of ' $X$ ' marks in the off-diagonal cells. An ' $X$ ' mark above the diagonal indicates that an assumption of information is required to start the activity. The DSM is particularly well suited to model the sequential and iterative informational relationships between activities in a product development process [56-58].

There are three possible relationship types between activities, so there are three corresponding DSM representation patterns, as is shown in Figure 1. When feed-forward information flows from A to B, place the mark at the intersection of column A and row B of the lower triangle. Conversely, when feedback information flows from $B$ to $A$, the mark is placed at the intersection of row $A$ and column $B$ of the upper triangle. When there is no information flow between $A$ and $\mathrm{B}$, the corresponding position is empty.

Partitioning is the manipulation of the matrix to eliminate or reduce feedback marks [58]. This process reorders activities so that dependencies are either below or close to diagonals. When this is done, a transparent structure for the network starts to emerge, allowing better planning of the project. We can see which activities are sequential, which ones can be done in parallel, and which ones are coupled or iterative [54].

Tearing is the process of choosing the set of feedback marks that, if removed from the matrix (and then the matrix is repartitioned), will render the matrix lower triangular [54]. Once the assumptions are made through tearing, the matrix is repartitioned for determining the preferred execution sequence [55].

Banding is the addition of alternating light and dark bands to a DSM to show independent (i.e., parallel or concurrent) activities (or system elements) [44]. The collection of bands or levels within a DSM constitutes the system/project [54].

\section{Research Methods}

It is necessary to adjust the process appropriately to complete the reconstruction project in a shorter time. The reconstruction project should follow the general requirements and procedures of engineering construction. Therefore, this study proposes an improved framework based on the process model of conventional construction projects. Firstly, it analyzes the owner's demand, construction goal, and activities relationships under the background of reconstruction, and then reorganizes activities to find a more suitable construction process for reconstruction. The framework includes four steps:

\subsection{Identify the target and determine the scope}

Establishing the model from the same reality varies under different purposes[59], so modeling must first identify the target. It is not easy to determine the owner's goals for post-disaster reconstruction projects because the requests from different stakeholders vary and even conflict with each other. But as mentioned above, time is almost recognized as the highest priority goal of post-disaster reconstruction projects[60]. In addition to this, completion within budget is also one of the goals that receive attention[20,27]. However, time, cost, and schedule goals cannot be met at the same time, and other goals will inevitably be damaged under the premise of highlighting one goal.

The paper expects to establish a process model for the rapid construction of reconstruction projects under time constraints and does not significantly reduce the performance of other targets. For example, the model cannot cancel the necessary quality assurance work to shorten the time but can only change the working relationship or merge the related work appropriately. In addition, the internal and external stakeholders are mainly concerned with completing the construction rather than the full life cycle of the project. Although the government's administrative approval and authorization are related to project implementation, they are also excluded from the study because they are beyond the management scope of contractors and owners. Finally, this research content is limited to the period from design to the completion of the project construction by the core organizations. It does not consider maintenance issues after the building is complete. 


\subsection{Break down project activities}

The ultimate goal of the research is to find an optimized workflow that is more suitable for the reconstruction scenario by analyzing the relationship between project work and make a more appropriate process or delivery method arrangement. The work breakdown structure (WBS) is a powerful structuring tool [61]. The paper uses WBS to decompose the project construction process to establish the activities relationships. As mentioned previously, the management of a reconstruction project is a specific expression of project management knowledge in the reconstruction environment and not be wholly separated from the project construction process. Therefore, this research applies the general project implementation process to specific reconstruction scenarios and optimizes the process through the calculation to find a delivery method that can quickly complete the reconstruction project. The regular work breakdown of the reconstruction project is shown in Figure 2.

\subsection{Identify activity relationships}

In order to reflect more detailed information, the activity relationship does not use the time sequence contact but the information relationship. An activity starts after receiving enough information generated or transmitted by another. Because the relationship is information constraint rather than time constraint, there is a possibility that discontinuous activities, even activities with large time intervals, will be rearranged together.

The study acquires the relationship through two aspects. One is the internal process requirements of regular project implementation activities. For example, construction activities need to receive design information before they can start. There is no information exchange between preparing and implementing procurement and providing construction sites. However, the project manager needs to adjust the process due to tighter time requirements, changes in the owner's functional requirements, and the dynamic nature of the reconstruction environment. Therefore, through the questionnaire survey of reconstruction project practitioners, some activity relationships in practice are identified. The respondents of the questionnaire included ten project managers who participated in post-disaster reconstruction and three university researchers. Unlike conventional projects, the owner's demands of reconstruction projects are very vague in the initial stage, and often they are constantly clarified in the design stage or even during construction. The activity relationship is reflected in the feed-forward and feedback information connection between design and daily construction.

Another example is that the specifications and models of the materials in the material list guide the implementation of procurement. However, when implementing procurement, procurers may find that the available resources in the market differ from the assumptions and need to be fed back to the material list for modification to continue subsequent construction. The activities relationship is shown in Figure 3.

\subsection{Build and optimize the model}

Sequencing the decomposed activities according to the primary order and marking out the feed-forward and feedback information forms an original DSM. The closely related activity blocks highlight using the DSM partition method to create the final optimized DSM. This study uses basic symbolic marks, which only indicate an information relation between the two activities but do not further indicate the strength of the information between the activities. The advantage is to strengthen the decision makers' understanding of project activities and help make decisions quickly. However, the disadvantage is that it can only reflect whether there is information transmission and the direction of transmission between activities but cannot reflect the closeness of the activities[55, 62]. It is not worth the time and cost of the decision-makers to collect a large number of actual contact strengths considering the urgency of the post-disaster reconstruction project. At the same time, the uncertainty of the reconstruction environment will weaken the stability of the strength information, so it is acceptable to use only marks for information. The DSM tool is DSM_Program-V2.1 to handle common DSM operations (partitioning, tearing, banding, simulation)[63]. The original DSM and optimized DSM are shown in Figure 4 and Figure 5.

\section{Discussion}

One major challenge for reconstruction is the availability of resources[64], which makes it difficult to shorten the construction period by increasing resource input. Large-scale reconstruction has increased the contradiction between resource demand and supply. The demand for resources increased drastically in a short period. At the same time, the collapse of the transportation system has hindered the input of external materials. The production and storage capacity of local resources has also been impaired due to disasters. It is challenging to increase resource input per unit of time and shorten the duration. Therefore, changing the reconstruction project's process and the delivery method seemed to be a viable option.

1. the design and construction should collaborate more closely under the post-disaster reconstruction environment. To implement the project as soon as possible, the owner must put forward project requirements and formulate a plan in a short time. Insufficiencies such as unclear requirements and fuzzy functions can only be clarified, fed back, and modified during the design process. The same situation also occurs between design and construction. When the construction environment is inconsistent with the design assumptions, the construction entity must feed information back and suspend the construct until it receives new drawings. When these two iterative cycles occur between different entities, long work interruptions will be inevitable.

The partitioned DSM reorganizes all activities without violating the inherent development law of the project and highlights the activities with strong correlation in the form of blocks. The detailed design and construction are partitioned in block three indicate the building should be closely coordinated with design and provide constructability suggestions. In practice, the reconstruction site is usually chaotic. The early entry of the construction entity can help expose design defects and adjust early. It can also help the construction group grasp the design intent and arrange resource procurement early. An early cooperative relationship establishes through a unified information sharing platform between different organizations [65]. Another method is to integrate the process into a single group[66,67]. Although the optimized DSM cannot wholly eliminate feedback and iteration in terms of process, it can simplify a single entity's internal loop through the internal management process. 
2. The partitioned DSM shows that the process has not fundamentally changed, and it still basically follows the route of identifying the owner's requirements, designing, and construction. The delivery method is not significant change and is still integrating and optimizing design, bidding, and construction. This is also in line with the researcher's view that an appropriate mature delivery method rather than an utterly unfamiliar one is more suitable for rebuilding the environment [7]. However, it is necessary to redesign the sequence of activities and establish a new workflow because of strict time constraints and a changeable project environment.

The partitioned blocks show that adjusting the position of specific activities in the process and grouping them into certain blocks for overall processing will produce better results in the reconstruction scenario. One change shown in Fig. 5 is procurement. Traditionally, most resources procurement tasks are implemented by contractors after the design is complete, and contractors can choose suppliers and product brands. Fig. 5 shows that when the designer can define the material parameters, the material procurement will be carried out without waiting for the bidding to select the contractor to compress time. Another change is that the construction plan is prepared in advance before the project team forms. Under the traditional delivery method, this adjustment is unreasonable. However, block 3 in partitioned DSM shows the feasibility of the early intervention in construction. Due to the changing environment of reconstruction and increasing uncertainty, construction personnel requires to intervene in the design early to increase the constructability of the design and reduce the probability of subsequent rework.

3. Bidding is still a necessary process, but it needs to be changed. For many years, the development of the design, bidding, and build of construction projects has proved its rationality and necessity. Although the reconstruction requires more rapid construction, a complete process is positively helpful for selecting competent contractors and ensuring the project's performance. The selection of contractors for reconstruction faces a dilemma. The suddenness and contingency of disasters make it difficult to achieve long-term and stable strategic cooperation common in conventional projects. In contrast, post-disaster reconstruction and the changeable environment need to ensure the contractor's capability and qualification. Setting the threshold can ensure the quality of the project and the smooth performance of the contract. Bidding is still an effective means to ensure the contractor's capabilities, but the reconstruction needs to adjust the content and scope.

The reconstruction environment has produced more communication of information between design and construction than in conventional projects. Review and selection of contractors in conventional projects should carry out after identifying qualified contractors and issuing bidding documents. However, the partitioned DSM shows that it should take precedence over these two tasks. This means that the owner should prepare the list of potential qualified contractors in advance instead of conducting competitive bidding to choose the contractors after the disaster. Furthermore, when the contractor is evaluated and selected before, the whole construction process will change, and the identification of qualified contractors and the issuance of tender documents can cancel. In addition, although bidding is still between detailed design and construction in the DSM, the effect of completing by one entity is better than individually because they are divided into one block. Therefore, the step of selecting a constructor through bidding can also be canceled. In this case, even if the owner needs bidding, the bidding effect of design and construction as a whole is better than that of construction bidding.

4. the reconstruction needs a more integrated process or delivery method to achieve the goal. The construction industry has always been regarded as fragmented[68]. Design, bidding, and construction are implemented and managed by professional entities, respectively, and there is a lack of practical cooperation among them. The traditional DBB method is low in integration[69, 70], and the owner signs contracts with all parties separately. Any new information beyond the original plan must be sent, received, processed, and finally returned through the intermediary of the owner. If the new data cannot be verified on-site, the cycle mentioned previously will repeat until the construction requirements are met. Therefore, the project time constantly delays in this information cycle.

Partitioned DSM shows the overlap between blocks, activities of different stages are rearranged in one block, and there may be multiple professional works in the block. It indicates that different professional work should be integrated to improve project performance. Although the integration requires higher professionals' capability, the information exchange of activities within a block is completed by themselves, thus the path of information transmission can reduce. Considering the significant changes in the reconstruction environment, the tight time, and the requirements of future economic development in the affected areas, the owner should pay more attention to the early planning, clarify the needs and project boundaries[71], and reduce the intervention in project implementation by reducing the number of contracts. Delivery methods such as EPC and DB reduce the number of contracts[72, 73], and the information cycle between designer and builder becomes the internal work of contractors. Therefore, EPC and DB are better than DBB in terms of integration, so they become the more appropriate options for the reconstruction project.

\section{Empirical Case}

\subsection{Introduction of the case}

On August 8, 2017, a magnitude 7.0 earthquake occurred in Jiuzhaigou County, Sichuan Province in China, causing a total of 8 counties in Sichuan Province and Gansu Province to be affected. The earthquake caused 8.043 billion yuan (1.245 billion US\$) direct economic loss and 20.85 billion yuan (3.228 billion US\$) indirect economic loss. The infrastructures such as transportation, communications, municipal administration, and public services were severely damaged. After the rescue and disaster relief, the reconstruction work started immediately. On November 6, 2017, the Sichuan Provincial Government put forward the earthquake recovery and reconstruction plan and listed the gymnasium in the project package. The total investment of the gymnasium is 70.8 million yuan (10.96 million US\$). In December 2017, the owner determined the project site and commissioned a survey and preliminary design immediately. The initial survey and preliminary design were completed in January 2018. On January 16, 2018, the project was publicly bid. The owner determined the winning bidder on February 14, 2018, and the construction began in March 2018. Finally, the project was delivered on August 13, 2019.

\subsection{The implementation processes}

Page 6/13 
Since the project was confirmed in November 2017, the owner has faced requirements from the government and the community, including:

1. The project must be completed and delivered before August 17,2019 , to host the planned sports meeting.

2. The functions provided by the project should be popular rather than professional to increase the degree of sports participation in the region.

3. The local government hopes to promote the local urbanization process and increase local employment through this reconstruction project.

The owner estimated that the project's total time would be as long as 775 days if the traditional method was used, and the expected completion time would exceed November 2019. Figure 6(a) shows the shortest total time estimated following conventional construction methods, in which the values of each stage are derived from the survey of projects of similar type and scale, the minimum time requirements in legal provisions, and the duration norm issued by the Ministry of Housing and Urban-Rural Development of the People's Republic of China.

To reduce the total period, the owner analyzed each stage's functional relationship and role and decided to change the work process and delivery method. Figure 6(b) shows the whole duration after adjusting the workflow. After analysis, the owner decided to take some measures:

In the plan released by the government, only the project was confirmed, but the site was not specified. Therefore, the owners' first problem was finding a suitable location while identifying their own needs. The owner decomposed it into two separate parts: finding the right site and identifying needs. One month after releasing the plan, the owner determined the site on December 7, 2017, and commissioned the company to conduct a site geological survey in December 2017. After analyzing the functions of the site survey, the owner divides the site geological survey into two parts: preliminary survey and detailed survey. The initial survey was placed after the site was selected and before the preliminary design to provided parameters for the preliminary design for structural analysis. The detailed survey is carried out simultaneously with the preliminary design, and the result is not only used as the input condition of the detailed drawing design, but also fed back to the preliminary design for correction.

The owner believed that it is difficult to express the requirements accurately, and it takes more time to entrust a consultant to identify the needs and the feasibility study. Therefore, the owner merged the identification requirements into the preliminary design. When entrusting the initial design, the owner only put forward basic needs. The needs include the gymnasium seats reach 3000 (including 2200 fixed and 800 active seats) for future operation, one formal basketball court on the ground and two training courts underground, all courts need be easily converted into badminton, table tennis, gymnastics. In communicating, the design drawings are iterated and revised constantly, and the owner's needs and goals gradually become clear. Finally, the preliminary design clarified the site geological conditions, functional requirements, total floor area and layout, personnel flow organization, structural design level, structural type, water supply power, electrical equipment power, and other professional basic requirements and parameters. These requirements are written into the bidding documents and become the contractor's work objectives and constraints.

On January 16,2018 , the owner published the tender notice on the public website. The bidding is a statutory procedure in China, which cannot be canceled or simplified. The owner expanded the delicate content and entrusted the contractor to complete the detailed design, material procurement, and construction. This method is less applied in post-disaster reconstruction in China, and experience accumulation is less. To reduce the probability of project failure, the owner evaluated the difficulty of project implementation and the number of capable contractors during the preliminary design, allowing contractors to participate in bidding as a single entity or joint venture, but must undertake detailed design, material procurement, and construction, etc. As the contractor was evaluated in advance, the contract signing time was shortened by about 15 days.

In the end, a joint venture formed by a design company and a construction company won the bid and became the EPC general contractor. After an in-depth analysis of the bidding documents and preliminary design documents, the general contractor believes that some issues may reduce the performance of the schedule and need to strengthen management. 1) The process and efficiency of information transmission between the designer and the construction staff; 2) The matching of design documents and construction; 3) The needs of the owner are easy to change. The general contractor took some corresponding measures

In response to problems such as deviations in understanding design documents by construction personnel and extended information transmission paths, the two companies sent personnel with similar project experience to set up a project management office on site. In the design process, the designer and the construction staff discussed the design details together. They strived to reduce misunderstandings and errors in the construction-the construction staff also timely feedback the deviation on-site to the designer for correction.

The general contractor allowed and encouraged construction personnel to put forward constructability suggestions during the design process to reduce items of difficulty to realize in the design drawings. Through this measure, construction feedback was shortened or eliminated, and rework and demolition caused by this were reduced.

The general contractor studied the bidding documents and discussed with the owner and the designer and believed that there were uncertainties in the details of the requirements and the choice of the project implementation plan by the owner, which may cause demand changed during implementation. Therefore, the general contractor strengthened the active communication between the designer, construction staff, and the owner and explained similar projects to the owner to help the owner make an early decision. Detailed design and construction are reduced by 85 days in total.

Figure 6 shows the estimated time for the initial plan and the actual time after the adjustment process. The comparison shows that using the proposed analysis framework to optimize the process reduced the total project duration by about $17 \%$. However, there are still shortcomings. The analysis is not detailed enough because it is the first time this framework tool has been used in a reconstruction project. The analysis only involves the main stage and fails to go into each stage's specific work or work package. Therefore, it was unable to optimize the work in-depth and to analyze the shortened time's performance from a quantitative perspective, such as the proportion of eliminating rework in the reduced time. 


\section{Conclusion}

Reconstruction is an urgent issue after the disaster. After small disasters, reconstruction is not much different from conventional projects and can be implemented following the construction process and requirements of ordinary projects. However, reconstruction projects face more complex situations after massive disasters or catastrophes, and the relationship between activities needs to be further optimized to meet delivery time and speed requirements. Many conventional project management methods need to be innovated to adapt to the new characteristics of the reconstruction project, including schedule control tools, cost estimation, and delivery methods. The mutual constraints of the overall restoration goals and the environmental chaos largely limited the owner's determination and construction scope.

There are many paths and methods to shorten the time of construction projects. under reconstruction circumstances, and it is difficult to shorten the project time by increasing resources. The more suitable option is to adjust the relationship between activities and change the delivery method to achieve time compression. In this paper, the relationship between activities of the reconstruction project is analyzed, and DSM establishes the model of activities in different stages of the reconstruction project. The partitioned DSM reorganized project activities. Some cross-stage activities have been adjusted closer, and a new relationship with the reconstruction scene has been revealed. The partitioned activity matrix indicates that a more integrated project delivery method such as EPC or DB should be adopted to meet the needs of the reconstruction situation.

\section{Declarations}

\section{Availability of data and materials}

The datasets generated and analysed during the current study are available from the corresponding author on reasonable request.

\section{Fund}

This research was funded by National Natural Science Foundation of China (No.71971147).

\section{Conflict of interest}

All the authors declare that they have no conflict of interest.

\section{Contributions}

Qingping Zhong and Chuan Chen conceived and designed the study, reviewed and edited the manuscript. Qingping Zhong and Hui Tang collected and organizє

\section{Informed consent}

All authors agree to submit this edition and declare that no part of this manuscript has been published or submitted elsewhere. We thank you for your consideration of our manuscript and look forward to receiving comments from the reviewers as soon as possible.

\section{References}

1. CRED (2020) Natural Disasters 2019.This document is available at. https://emdat.be/ sites/default/files/adsr_2019.pdf, B. CRED, Editor.

2. McKim R, Attalla M (1998) Reconstruction of occupied buildings, project control techniques-A Canadian study. In Proc., 1st Int. Conf. on Civil Engineering, : p. pp. 439-453

3. Attalla M, Hegazy T, Elbeltagi E (2004) -house delivery of multiple-small reconstruction projects. J Manag Eng 20(1):25-31

4. Labadie JR (2008) Auditing of post-disaster recovery and reconstruction activities. Disaster Prevention and Management: An International Journal 17(5):575-586

5. Norling B (2013) Effective time management in post-disaster reconstruction. in Australian and New Zealand Disaster and Emergency Management Conference.

6. PMI (2017) a guide to the peoject management body of knowledge(PMBOK guide). sixth edition, 6th edn. project management institute

7. Myburgh D, Wilkinson S, Seville E (2008) Post-Disaster Reconstruction Research in New Zealand: An industry update.

8. Himayatullah K, Vasilescu LG, Asmatullah K (2008) DISASTER MANAGEMENT CYCLE - A THEORETICAL APPROACH. Management and Marketing Journal 6(1):43-50

9. Alexander DE (2002) Principles of Emergency Planning and Management. [Oxford University Press]

10. Manyena SB (2006) The concept of resilience revisited. Disasters 30(4):434-450

11. Paton D, Smith L, Violanti J (2013) Disaster response: risk, vulnerability and resilience. Disaster Prevention \& Management 9(3):173-180

12. UNISDR (2005) Hyogo Framework for 2005-2015: Building the Resilience of Nations and Communities to Disasters.

13. Gunawardena T et al (2014) TIME-EFFICIENT POST-DISASTER HOUSING RECONSTRUCTION WITH PREFABRICATED MODULAR STRUCTURES. Open House International 39(3):59-69

14. FEMA. National Disaster Recovery Framework(2nd Edition) (2016) ; Available from:

15. Freeman PK (2004) Allocation of post-disaster reconstruction financing to housing. Building Research and Information 32(5):427-437 
16. Fengler W, Ihsan A, Kaiser K (2008) Managing Post-Disaster Reconstruction Finance-International Experience in Public Financial Management. The World Bank

17. Saya S et al (2017) Build Back Better: In recovery, rehabilitation and reconstruction.

18. Kennedy J et al (2008) The meaning of 'build back better': evidence from post-tsunami Aceh and Sri Lanka. J Contingencies Crisis Manag 16(1):24-36

19. Ophiyandri T et al (2013) Critical success factors for community-based post-disaster housing reconstruction projects in the pre-construction stage in Indonesia. International Journal of Disaster Resilience in the Built Environment 4(2):236-249

20. Adamy A, Bakar AHA (2019) Key Criteria for Post-Reconstruction Hospital Building Performance. in IOP Conference Series: Materials Science and Engineering. IOP Publishing

21. Hidayat B, Egbu C (2011) Critical Success Factors Associated With Post-Disaster Reconstruction Projects. in Procs 27th Annual ARCOM Conference.

22. Sadiqi Z, Coffey V, Trigunarsyah B (2011) Post-disaster Housing Reconstruction: Challenges for community participation. in Proceedings of the international conference on Building Resilience: interdisciplinary approaches to disaster risk reduction, and the development of sustainable communities.

23. Twigg J (2009) Characteristics of a disaster-resilient community: a guidance note (version 2).

24. Chang $Y$ et al (2012a) Managing resources in disaster recovery projects. Engineering, Construction and Architectural Management 19(5):557-580

25. Chang Y et al (2012) Resourcing for post-disaster reconstruction: a comparative study of Indonesia and China. Disaster Prevention and Management 21(1):7-21

26. Hidayat B, Egbu C (2010) A literature review of the role of project management in post-disaster reconstruction. in Procs 26th Annual ARCOM Conference. Association of Researchers in Construction Management

27. Aliakbarlou S et al (2018) Conceptual Client Value Index for Post Disaster Reconstruction Contracting Services. KSCE J Civ Eng 22(4):1067-1076

28. Ismail D et al (2014) Project management success for post-disaster reconstruction projects: international NGOs perspectives. Procedia Economics and Finance 18:120-127

29. Francis TR et al (2018) Post-disaster reconstruction in Christchurch: a "build back better" perspective. International journal of disaster resilience in the built environment 9(3):239-248

30. Kulatunga U (2011) Project Management of Disaster Reconstruction. Wiley-Blackwell

31. Olshansky RB, Hopkins LD, Johnson LA (2013) Disaster and Recovery: Processes Compressed in Time. Nat Hazards Rev 13:173-178

32. Fayazi M et al (2017) Managing institutional fragmentation and time compression in post-disaster reconstruction - the case of Bam. International Journal of Disaster Risk Reduction 21:340-349

33. Moselhi O (1993) Schedule compression using the direct stiffness method. Can J Civ Eng 20(1):65-72

34. Moselhi O, Roofigari-Esfahan N (2012) Compression of project schedules using the analytical hierarchy process. Journal of Multi-Criteria Decision Analysis 19(1-2):67-78

35. Lamberson LR, Hocking RR (1970) Optimum Time Compression in Project Scheduling. Management Science, 16(10): p. B-597-B-606

36. Fazio $P$ et al (1988) FAST-TRACKING OF CONSTRUCTION PROJECTS - A CASE-STUDY. Can J Civ Eng 15(4):493-499

37. Lee EB, Lee H, Harvey JT (2006) Fast-track urban freeway rehabilitation with 55-h weekend closures: I-710 long beach case study. J Constr Eng Manag 132(5):465-472

38. Bissiri Y (2000) Fast-track approach to mining construction projects.Mining Engineering,

39. Gerry E (2002) The fast track manual: A guide to schedule reduction for clients and contractors on engineering and construction projects. ed. E.C. Inst

40. Roemer TA, Ahmadi R (2004) Concurrent crashing and overlapping in product development. Oper Res 52(4):606-622

41. Bogus SM, Molenaar KR, Diekmann JE (2005) Concurrent engineering approach to reducing design delivery time. J Constr Eng Manag 131(11):11791185

42. Molenaar K, Franz B (2018) Revisiting Project Delivery Performance. Charles Pankow Foundation, Construction Industry Institute, University of Colorado, University of Florida,

43. Touran A et al (2011) Selection of Project Delivery Method in Transit: Drivers and Objectives. J Manag Eng 27(1):21-27

44. Grose D (1994) Reengineering the aircraft design process. 5th Symposium on Multidisciplinary Analysis and Optimization, : p. 4323

45. Forbes $\mathrm{GA}$ et al (2003) The optimisation of a strategic business process.

46. Eppinger SD, Browning TR (2012) Design Structure Matrix Methods and Applications, vol 1. Mit Press Books

47. Maheswari JU, Varghese K (2005) A Structured Approach to Form Dependency Structure Matrix for Construction Projects. in International Symposium on Automation \& Robotics in Construction.

48. Zhang Y, Flood I (2014) Planning and Scheduling Prefabrication Construction Projects Using Dependency Structure Matrix (DSM). in International Conference on Computing in Civil and Building Engineering. 2014

49. Eppinger SD, Salminen V (2001) Patterns of Product Development Interactions. Proceedings of Iced ', : p. 283-290

50. Gunawan I, Ahsan K (2010) Project scheduling improvement using design structure matrix. International Journal of Project Organisation and Management 2(4):311-327

51. Chen CH, Ling SF, Chen W (2003) Project scheduling for collaborative product development using DSM. Int J Project Manage 21(4):291-299

52. Maheswari JU, Varghese K (2005) Project Scheduling using Dependency Structure Matrix. Int J Project Manage 23(3):): p. 223-230

53. Browning TR (2016) Design Structure Matrix Extensions and Innovations: A Survey and New Opportunities. IEEE Trans Eng Manage 63(1):27-52

Page $9 / 13$ 
54. Yassine A (2004) An Introduction to Modeling and Analyzing Complex Product Development Processes Using the Design Structure Matrix (DSM) Method. 9

55. Yassine A, Braha D (2003) Complex concurrent engineering and the design structure matrix method. Concurrent Engineering 11(3):165-176

56. Sullivan J (2010) Application of the Design Structure Matrix (DSM) to the real estate development process.

57. Steward D (1981b) Systems Analysis and Management: Structure, Strategy, and Design.

58. Steward DV (1981a) The design structure system: A method for managing the design of complex systems. IEEE Trans Eng Manage 28(3):71-74

59. Jablonka E (2007) The Relevance of Modelling and Applications: Relevant to Whom and for What Purpose?

60. Alsaadi O, Acar E (2016) Using Construction Project Management Know-how for Disaster Recovery Projects - A Synthesis of Literature.

61. Chua DK, Godinot M (2006) Use of a WBS matrix to improve interface management in projects. J Constr Eng Manag 132(1):67-79

62. Browning TR (2001) Applying the design structure matrix to system decomposition and integration problems: a review and new directions. IEEE Trans Eng

Manage 48(3):292-306

63. https://dsmweb.org/. DSM_Program-V2.1. [cited (2020 10.10]) ; Available from: https://dsmweb.org/excel-macros-for-partitioning-und-simulation/

64. Chang $Y$ et al (2011) Identifying factors affecting resource availability for post-disaster reconstruction: A case study in China. Construction Management

and Economics 29(1):37-48

65. Oduyemi O, Okoroh MI, Fajana OS (2017) The application and barriers of BIM in sustainable building design. Journal of Facilities Management 15(1):1534

66. Arashpour $\mathrm{M}$ et al (2015) Optimization of process integration and multi-skilled resource utilization in off-site construction. Autom Constr 50:72-80

67. Flager $\mathrm{F}$ et al (2009) Multidisciplinary process integration and design optimization of a classroom building. Journal of Information Technology in Construction (ITcon) 14(38):595-612

68. Fellows R, Liu AM (2012) Managing organizational interfaces in engineering construction projects: addressing fragmentation and boundary issues across multiple interfaces. Construction management and economics 30(8):653-671

69. El Asmar M, Hanna AS, Loh WY (2013) Quantifying Performance for the Integrated Project Delivery System as Compared to Established Delivery

Systems.Journal of Construction Engineering and Management, 139(11)

70. Pocock JB (1996) The relationship between alternative project approaches, integration, and performance. AIR FORCE INST OF TECH WRIGHTPATTERSON AFB OH

71. Da Silva J (2010) Key considerations in post-disaster reconstruction. Citeseer

72. Gransberg DD, Koch JE, Molennar KR (2006) Preparing for design-build projects. American Water Works Association, 10.1061/9780784408285: p. 31-66

73. Gordon CM (1994) Choosing appropriate construction contracting method. J Constr Eng Manag 120(1):196-210

\section{Figures}

\section{Three Configurations that Characterize a system}

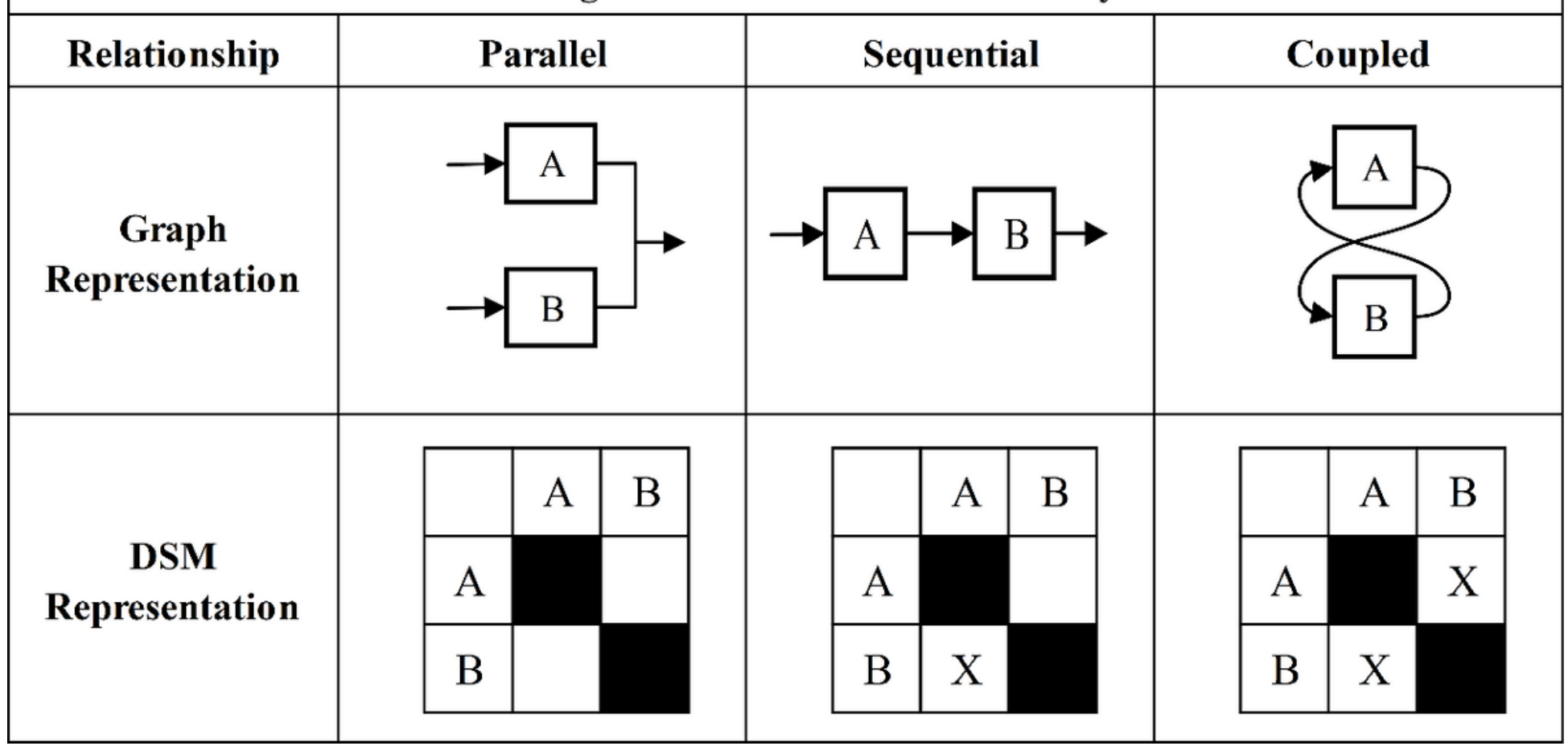

Figure 1 


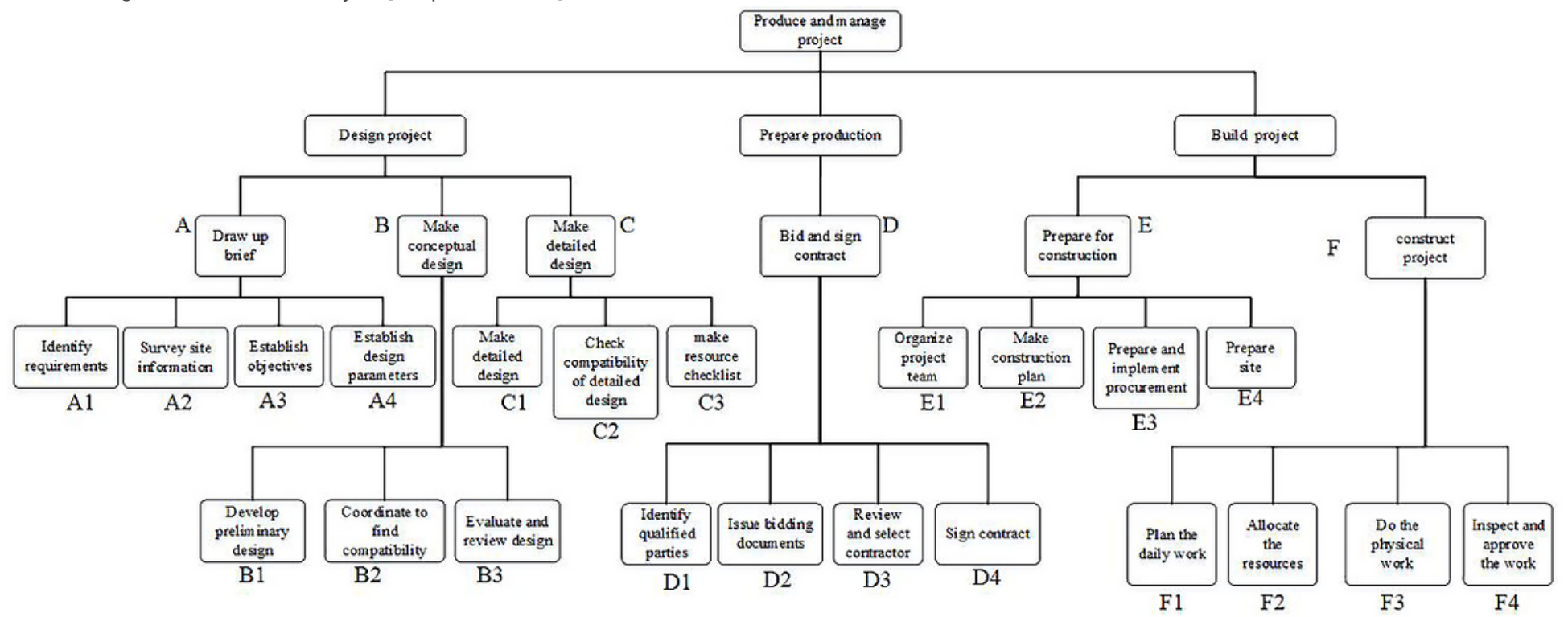

Figure 2

The Hierarchical Work Breakdown of the Project Process

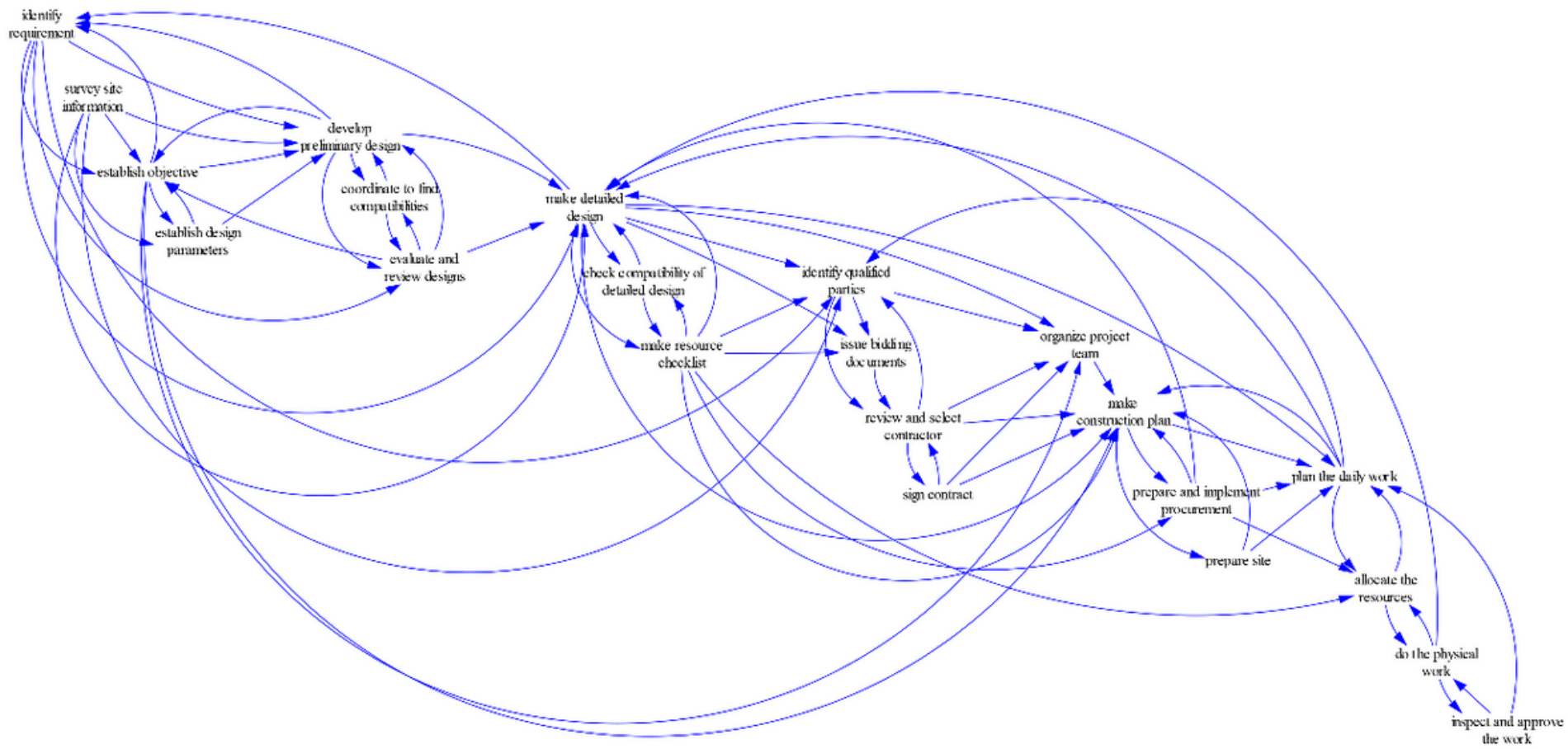

Figure 3

The Relationship between Activities in Post Disaster Reconstruction 
establish design parameters

develop preliminary design

coordinate to find compatibilities

evaluate and review design

make detailed design

check compatibilities of detailed design

make resource check1ist

identify qualified parties

issue bidding documents

review and select contractor

sign contract

organize project team

make construction plan

prepare and implement procurement

prepare site

plan the daily work

a1locate the resources

do the physical work

inspect and approve the work

\begin{tabular}{l|l|l|l|l|l|l|l}
1 & 2 & 3 & 4 & 5 & 6 & 7 & 8 \\
\hline 1 & & 1 & & 1 & & & 1 \\
\hline & 2 & & & & & & \\
\hline 1 & 1 & 3 & 1 & 1 & & 1 & \\
\hline & 1 & 1 & 4 & & & & \\
\hline 1 & 1 & 1 & 1 & 5 & 1 & 1 & \\
\hline 1 & & & & 1 & 6 & 1 & \\
\hline 1 & 1 & & & 1 & & 1 & 8
\end{tabular}

\begin{tabular}{|l|l|l|l|l}
\hline C1 & 8 & 1 & 1 \\
\hline
\end{tabular}

\begin{tabular}{l|l|l|l|l}
1 & 8 & 1 & 1 \\
\hline
\end{tabular}

\begin{tabular}{l|l|l|l|l|l|}
1 & 9 & 1 \\
\hline
\end{tabular}

\begin{tabular}{|l|l|l|l|l|l|l|l|l|l|l|l|} 
C3 & 10 & & & & & & & & 1 & 1 & 10 \\
\hline
\end{tabular}

\begin{tabular}{|l|c|c|c|l|l|l|l|l|l|l|l|l|l|} 
D1 & 11 & 1 & 1 & & & & & & 1 & & 1 & 11 & \\
D2 & 12 & & & & & & & & 1 & & 1 & 1 & 12
\end{tabular}

D3 13

D4 14

\begin{tabular}{|l|l|l|l|l|l|}
\hline E1 & 15 & & & 1 \\
\hline E2 & 16 & & & 1 \\
\hline
\end{tabular}

E3 17

\begin{tabular}{|l|l|}
\hline E4 & 18 \\
\hline
\end{tabular}

F1 19

F2 20 |

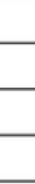

\begin{tabular}{|c|l|l|l|l|c|c|c|} 
& & & 1 & 1 & 13 & 1 & \\
\hline 1 & & & 1 & & 1 & 1 & 15 \\
\hline 1 & & 1 & & & 1 & 1 & 1 \\
\hline
\end{tabular}

\section{Figure 4}

The Original DSM for Post Disaster Reconstruction

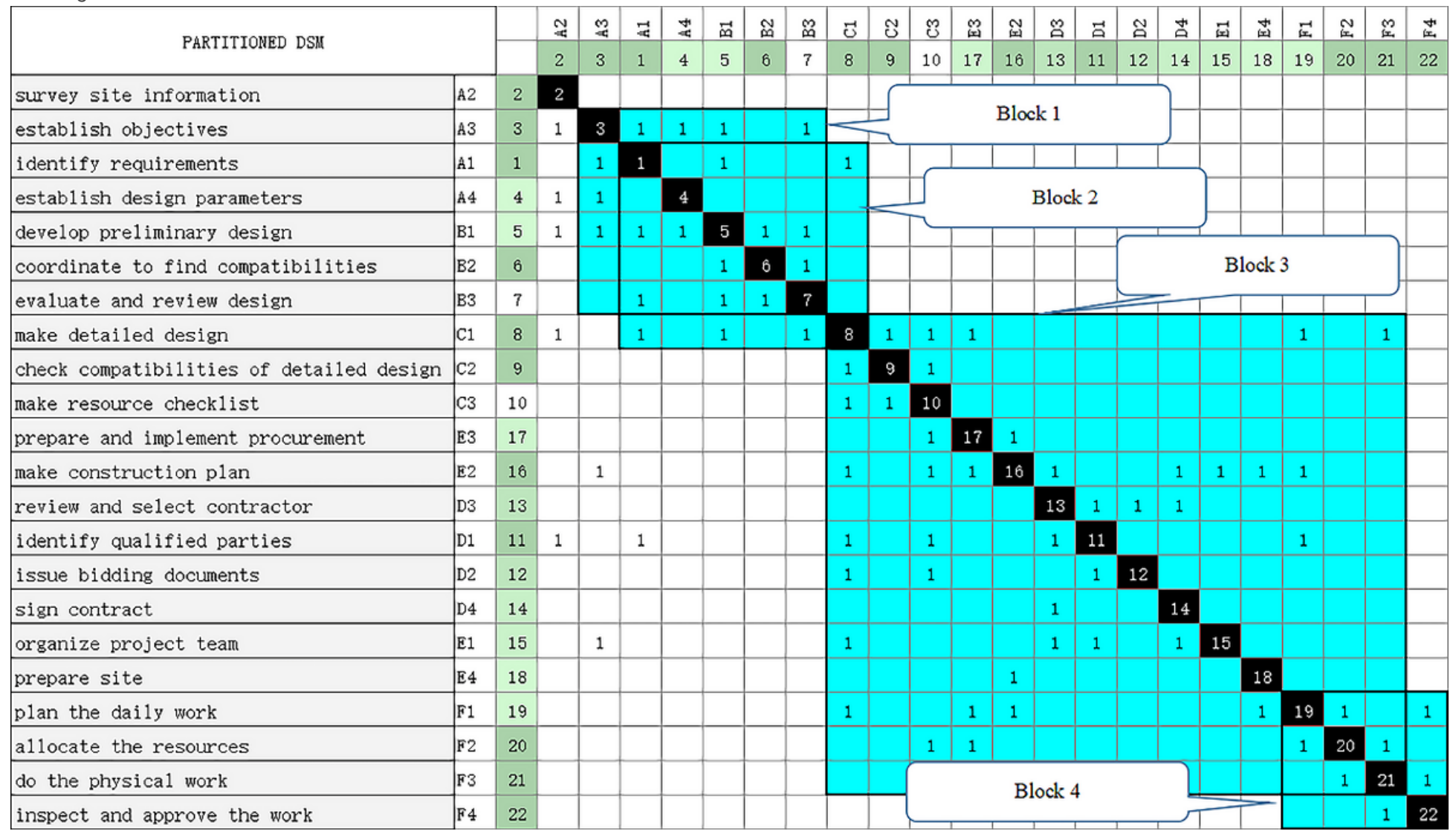

Figure 5

The Optimized DSM for Post Disaster 


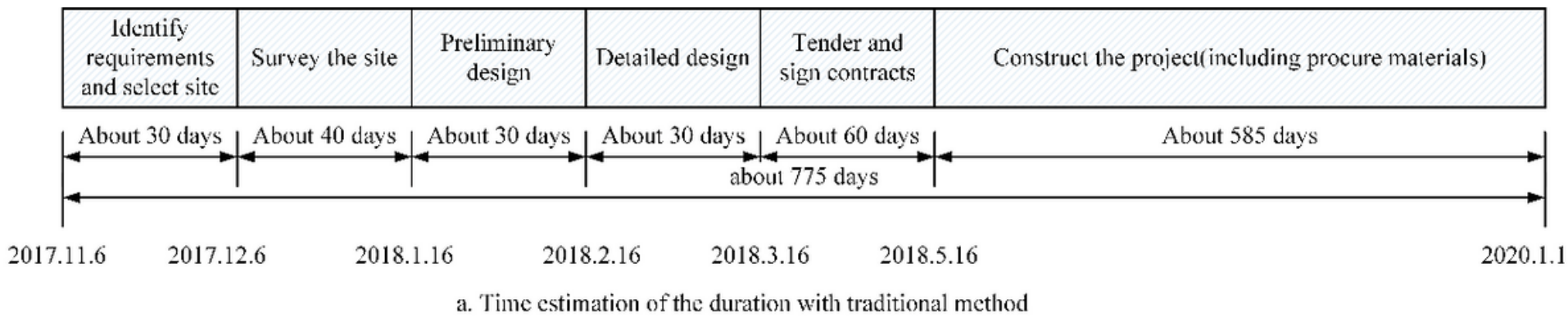

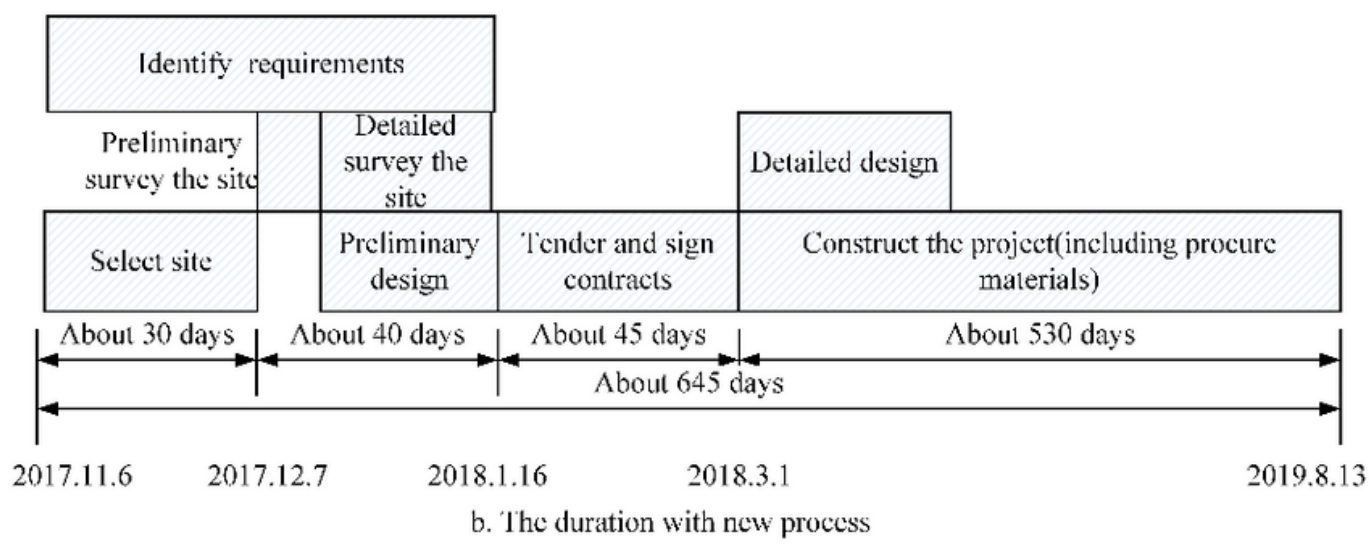

Figure 6

The Estimation and Actual Time of the Case Project 